\title{
Espaços educadores sustentáveis: um retrato dos processos educativos ${ }^{1}$
}

\author{
Sustainable educating spaces: \\ a picture of educational processes
}

Cristina Machado OLIVEIRA ${ }^{2}$

Fatima Elizabeti MARCOMIN ${ }^{3}$

\begin{abstract}
Resumo
$\mathrm{O}$ artigo retrata processos educativos evidenciados na Pousada Vitória e Gaia Village (ambos em SC/Brasil) e NaturGut Ophoven (Alemanha), visando à constituição de Espaços Educadores Sustentáveis. A pesquisa qualitativa, pautada na Fenomenologia da Percepçáo, envolveu entrevistas junto às coordenadoras, observação participante, estudo dos registros de campo e dos documentos. Dentre os processos, emergem: vivências em museu interativo, espaços de convivência e ao ar livre; estimular atividades na agricultura orgânica, manejo sustentável; bioconstrução; inclusão de pessoas de diferentes situações econômicas, nacionalidades e culturas. Vislumbramos a imersão em uma Educação Ambiental que abrigue a dimensão afetiva e transcendental do ser humano.
\end{abstract}

Palavras-chave: Educação e sustentabilidade. Educação ambiental. Espaços educadores sustentáveis.

\begin{abstract}
The article portrays educational processes evidenced in Vitoria Inn and Gaia Village (both in SC/Brazil) and NaturGut Ophoven (Germany), aiming at the establishment of Sustainable Educating Spaces. The qualitative research based on the Phenomenology of Perception, involved interviews with the coordinators, participant observation, study of field records and documents. Among the processes, emerge: experiences in interactive museum, living spaces and outdoors; stimulate activities in organic agriculture, sustainable management; bioconstruction; inclusion of people from different economic backgrounds, nationalities and cultures. We glimpse the immersion in an Environmental Education that houses the affective and transcendental dimension of the human being.
\end{abstract}

Key words: Education and sustainability. Environmental education. Sustainable educating spaces.

1 Estudo financiado com bolsa da Fundação de Amparo à Pesquisa e Inovação do Estado de Santa Catarina.

2 Mestra em Educação. Escola de Educação Básica Prefeito Luiz Carlos Luiz. https://lattes.cnpq. br/0698416508663590 https://orcid.org/0000-0002-0992-1581 E-mail: cristina.oliveira.kiti@gmail.com

3 Doutora em Ciências pelo Programa de Pós-Graduação em Educação - Universidade do Sul de Santa Catarina (PPGE-Unisul). https://lattes.cnpq.br/1185445232833748 https://orcid.org/0000-0001-62172754 E-mail: fatimaelizabetimarcomin@gmail.com 


\section{Introduzindo a pesquisa}

No atual contexto de discussões acerca da educação e da sustentabilidade, tanto no âmbito nacional quanto internacional, evidencia-se a necessidade do desenvolvimento e materialização de novos meios e estruturas educativas que estreitem a relação entre ambiente e sociedade. É fundamental estabelecer processos de ensino-aprendizagem que contemplem as múltiplas inter-relaçóes entre os diferentes aspectos socioambientais e potencializem a capacidade de desenvolvermos açóes em espaços educadores intencionalmente criados para este fim. Trajber e Sato (2010) elucidam que, quando tais espaços são constituídos de modo a se auto manterem e operarem por meio de açóes sustentáveis, reduzindo impactos negativos à sociedade e ao meio ambiente, estes são denominados Espaços Educadores Sustentáveis.

Seja no âmbito da educação formal, como no caso das escolas, ou referente à educação não formal, como em lugares da comunidade, ecossistemas ou outros espaços (museus, fazendas, pousadas, centros, espaços públicos e privados), os Espaços Educadores Sustentáveis, de acordo com a concepção de Trajber e Sato (2010), podem constituir-se em lugares não apenas projetados para serem sustentáveis, mas, também, promotores de educação para a sustentabilidade. Para as autoras, lugares com vivências concretas que convidem à reflexão sobre o modelo de vida vigente na sociedade, seus impactos nas relaçóes entre as pessoas e delas com o ambiente, e sobre como é possível estabelecer novas formas de existência mais justas, equânimes e favoráveis à dinâmica ecológica da Terra. Isso é "[...] um convite à ressignificação de nossos modos de vida" (TRAJBER; SATO, 2010, p. 71).

No atual contexto educacional brasileiro, vimos derrocadas conquistas de décadas à educação e, em particular, à Educação Ambiental. Num panorama em que lutávamos pela consolidação das Diretrizes Curriculares Nacionais de Educação Ambiental (BRASIL, 2012), hoje necessitamos lutar - mais do que nunca - para que os espaços educadores sejam inovadores, críticos, que contemplem uma educação inclusiva, de qualidade e, acima de tudo, justa. Que sejam capazes de superar ideias retrógradas que impedem o desenvolvimento pleno e livre dos processos de ensino e aprendizagem; que possibilitem a emancipação ao invés do controle e da dominação.

Nessa perspectiva, vimos propor, à luz da pesquisa realizada, a reflexão acerca da constituição e implantação de Espaços Educadores Sustentáveis, descortinando a seguinte questão: que processos educacionais emergem à constituição destes espaços? $\mathrm{Na}$ busca deste entendimento, apresentamos um retrato dos espaços pesquisados com vistas a contribuir com a temática e oferecer subsídios/sugestóes de como esses processos podem ser consolidados frente à realidade brasileira. 
A pesquisa retrata os processos evidenciados na Pousada Vitória (Figura 1) e Gaia Village (Figura 2), ambas em Santa Catarina, Brasil, e Naturgut Ophoven, na Alemanha (Figura 3).

\section{Figura 1 - Pousada Vitória}

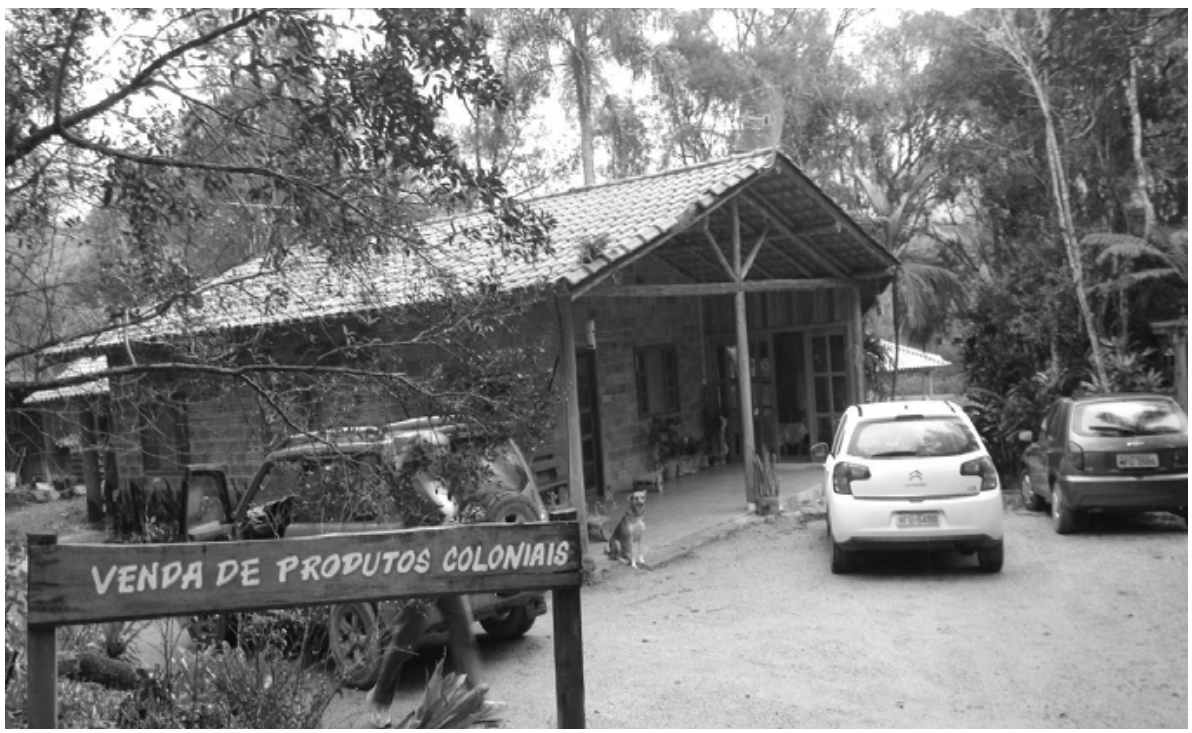

Fonte: Acervo da pesquisadora, 2015.

Figura 2 - Projeto Gaia Village

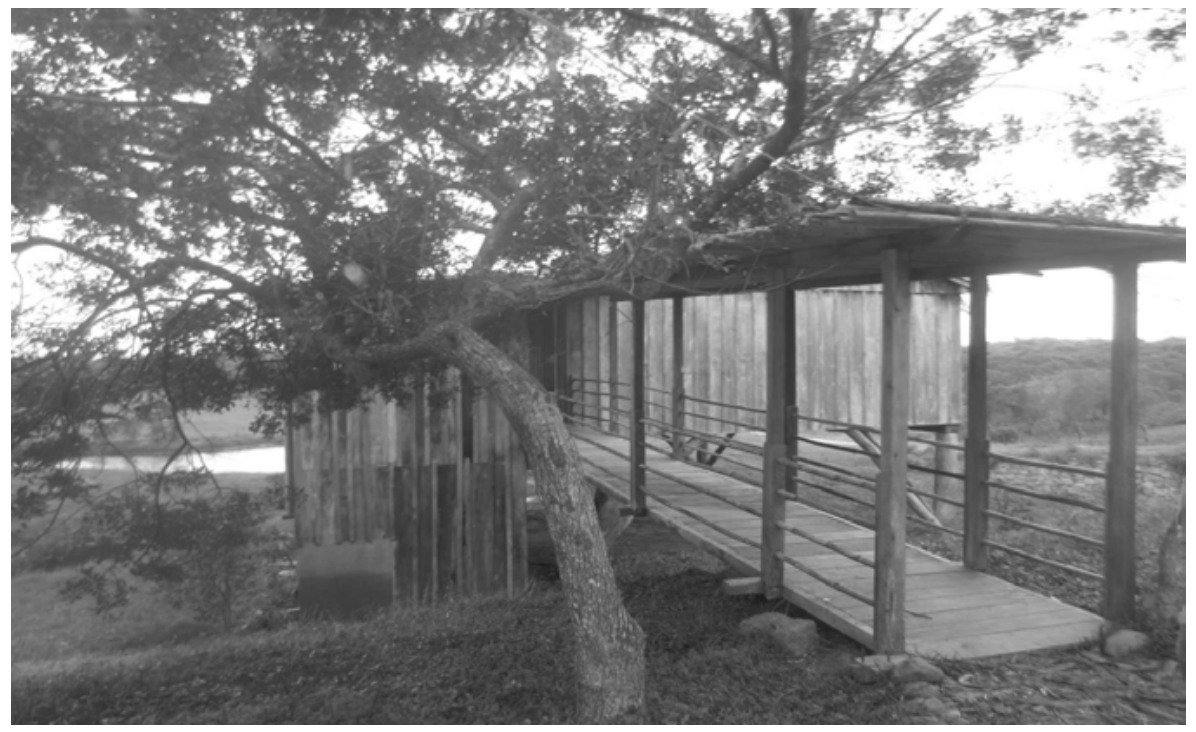

Fonte: Acervo da pesquisadora, 2015. 
Figura 3 - NaturGut Ophoven

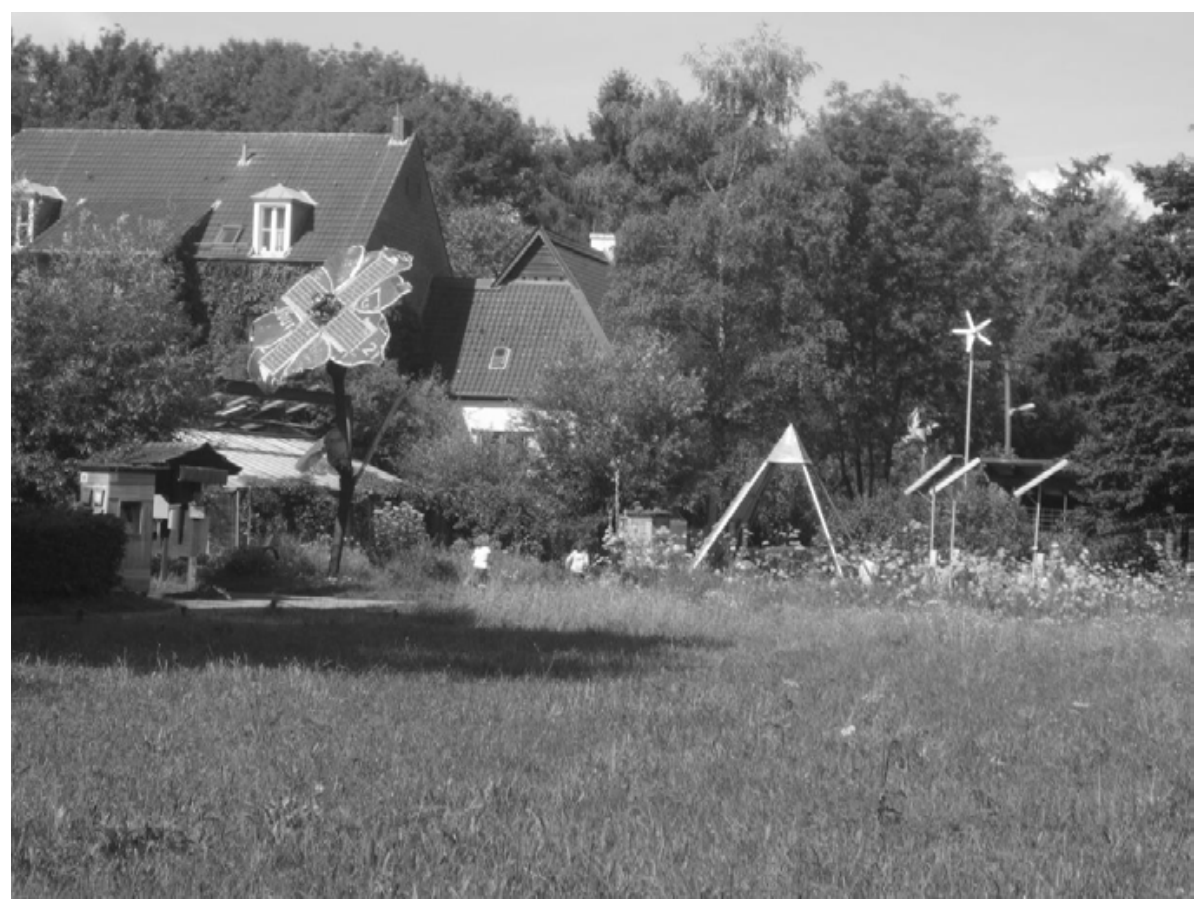

Fonte: Acervo da pesquisadora, 2015.

\section{O percurso trilhado}

Os espaços estudados compreendem o NaturGut Ophoven, situado no centro do ambiente urbano de Leverkusen, na Renânia do Norte-Westfália (Alemanha); a Pousada Vitória, localizada em ambiente rural de Mata Atlântica em Santa Rosa de Lima (Santa Catarina - Brasil); e Projeto Gaia Village, que se encontra em paisagem rural e litorânea no município de Garopaba (Santa Catarina - Brasil). A escolha por tais espaços se deu pelo fato de estes possuírem experiência e há mais de uma década trabalharem com a sustentabilidade ea educação em seus projetos, contribuindo para um conhecimento mais abrangente das potencialidades e desafios relacionados aos processos na formação de Espaços Educadores Sustentáveis.

A abordagem metodológica qualitativa foi pautada na Fenomenologia da Percepção Merleau-Pontyana (1999), cujo delineamento interpretativo decorreu de adaptaçóes dos métodos de Colaizzi (1978) e Sanders (1982), apresentados por Moreira (2002). 
O método sugerido por Sanders considera como "estrutura fenomenológica de pesquisa" (MOREIRA, 2002, p. 121) a determinação do objeto de pesquisa e dos sujeitos; a busca de informaçóes por meio de entrevistas, estudo documental e técnicas de observação participante; e a "análise fenomenológica dos dados". Entretanto, para efeitos desta pesquisa, propusemos, ao invés de uma "análise fenomenológica" das informações, uma "interpretação fenomenológica" com base em Sato (2013, c. p.), por considerarmos, a exemplo dessa autora, a não fragmentação do fenômeno, mas a interpretação/compreensão do fenômeno em sua totalidade.

No método proposto por Colaizzi, o estudo e interpretação fenomenológicos envolvem descriçôes das experiências vividas; a "extração de assertivas significativas", que corresponde à extração de frases ditas pelos sujeitos entrevistados que tenham relação direta com o fenômeno em estudo; a "formulação de sentidos" a partir destas sentenças, que buscam dar significado ao que os sujeitos dizem; e a organização destes sentidos em "conjuntos de temas" (MOREIRA, 2002, p. 121) que sustentarão a descrição do fenômeno.

O estudo documental foi realizado a partir de folders, relatórios, websites e cartilhas visando a extrair as informaçóes principais neles contidas. Também, foi vivenciada a observaçáo participante de atividades educativas nos lugares visitados, e realizadas entrevistas com as coordenadoras (Dida, Sandra e Ute) dos espaços estudados, sendo estas transcritas fielmente.

Ainda, pelo viés de uma adaptação do método de Sanders, incluímos outra fonte importante de informaçóes, o diário de campo com os registros de todas as observaçôes durante o período de visitas técnicas.

Neste recorte da pesquisa, há a utilização de informações das entrevistas, da observação participante, do estudo dos documentos e do diário de campo. Houve um agregar destas informaçóes em conjuntos textuais no que Sato (2013, p. 23) considera uma "espiral de conhecimentos", num adensar ascendente. Na presente pesquisa, com base nesse "movimento" em espiral de conhecimentos que integra o estudo, interpretação e descrição dos fenômenos perceptivos, foram escritos conjuntos textuais que relacionam os relatos dos diferentes atores, as descriçóes dos espaços e seus processos, as nossas observaçóes e os relatos do diário de campo.

O conjunto textual dos processos englobou: as abordagens de sustentabilidade e de Educação Ambiental, os temas trabalhados nesses espaços, as atividades realizadas e os projetos futuros. O panorama evidenciado foi entremeado pelas "falas" das coordenadoras entrevistadas dos espaços estudados, bem como por elementos textuais dos documentos e dos registros de campo. 


\section{Os processos educacionais nos espaços estudados}

A descrição dos processos educacionais observados segue uma redação fluida no formato dissertativo, sem o engessamento do fenômeno, mas priorizando a essência do observado/interpretado, já que na concepção Merleau-Pontyana (1999) o perceber arrasta consigo o percebido e, portanto, não há limites bem delineados entre eles, passíveis de estabelecimento claro, onde um ou outro se inicia.

As açóes realizadas nos três espaços estudados seguem uma perspectiva educativa voltada para o conhecimento e conservação do meio ambiente, para o bem-estar das pessoas e para a sustentabilidade socioambiental, cada qual com uma concepçáo própria conceitual e de abordagem acerca da sustentabilidade e da Educação Ambiental. Considerando a perspectiva Merleau-Pontyana (1999), os sujeitos vivem o mundo com sua própria subjetividade, mas, ao mesmo tempo, em inter-relação com as subjetividades das outras pessoas. Ao experimentar o mundo de formas diferentes (impregnadas de sentidos, emoçóes e memórias), elas podem abordar concepçóes distintas que influenciam na sua maneira de se relacionar com o meio ambiente e com a sociedade, de considerar diferentes temáticas e perspectivas futuras - elementos que transparecem nos achados desta pesquisa.

No que se refere à sustentabilidade, as concepções e abordagens nos três espaços transitam no sentido de buscarem reduzir os impactos gerados pela atividade humana e ao meio ambiente, contudo diferem entre si pela ênfase dada aos aspectos que envolvem este processo. $\mathrm{Na}$ Pousada Vitória, a proprietária (Dida) conta que se preocupa mais com a sustentabilidade do meio ambiente, mas não descarta a relevância da questão econômica para gastos importantes, como o estudo dos filhos. Para a coordenadora do NaturGut Ophoven (Ute), a abordagem do Centro na Alemanha busca os aspectos social, ambiental e econômico em todos os projetos, porém ressalta uma ênfase maior às questóes social e ambiental. A coordenadora do Gaia Village (Sandra) argumenta criticamente a respeito da abordagem que concebe a sustentabilidade como um tripé econômico, social e ambiental. Alega que o termo sustentabilidade, no seu entendimento, vem sendo mal-empregado:

A gente discorda daquele tripé da sustentabilidade: 'Ah, a sustentabilidade é baseada no tripé econômico-social-ambiental!' Acredito que a verdade é que a questão ambiental não é tripé, a questão ambiental é base. A partir do ambiente equilibrado, conservado, justo e que seja mais igualitário, se consegue desenvolver os aspectos sociais e econômicos com parcimônia. [...] Que no ambiente devastado você não vai ter justiça social, equidade, não vai ter desenvolvimento social, muito menos desenvolvimento. Pode até ter desenvolvimento econômico num ambiente devastado, mas ele tem vida curta. Ele não vai se manter, não vai ter retorno. Então, hoje, a gente não usa mais a palavra 'sustentável'. Nessa questão, pela nossa 
prática, a gente poderia dizer que a gente trabalha mais com a questáo, realmente, do socioambiental. Não tem como separar. E o socioambiental também naquela: a sociedade como protagonista [sic] (Sandra, c. p.).

A concepção da coordenadora do Gaia Village vem ao encontro de uma compreensão crítica defendida por Sato (2013) a respeito do termo sustentabilidade, ao considerar que somente com ambientes ecologicamente saudáveis e inclusão social é possível prosperar em outros aspectos sociais, como a justiça social e a economia com equidade.

Mesmo expressando uma compreensão crítica ao mau uso do termo sustentabilidade, acoordenadora do Projeto Gaia Village não vê problemas em se desenvolver, também, economicamente a partir do cuidado com o ambiente. Para Trajber e Sato (2010), o cuidado, aintegridade nas açôes refletidas e o diálogo são princípios fundamentais à formação de Espaços Educadores Sustentáveis, e pensamos serem também pertinentes às atividades que envolvam aspectos econômicos e de autossuficiência.

O modo como os espaços abordam a sustentabilidade, possivelmente, influencia na forma como estes espaços concebem a Educação Ambiental. Na Pousada Vitória, a concepção de Educação Ambiental está profundamente relacionada com o respeito à vida, o respeito às florestas, o respeito à Natureza. Isso corrobora a concepção de Sauvé e Orellana (2006, p. 277, tradução nossa), quando dizem que, na Educação Ambiental, "[...] o meio ambiente não éum tema, mas uma realidade cotidiana e vital"4 e que ela "[...] se situa no centro de um projeto de desenvolvimento humano" na "[...] esfera de relação a Oikos (eco), a casa de vida compartilhada na qual existe uma forma de alteridade relacionada com a rede de outros seres vivos". ${ }^{6}$

Para Dida (c. p.), a Educação Ambiental acontece naturalmente, sem a necessidade de ficar "citando a questâo de Educação Ambiental", pois para ela as experiências e práticas já traduzem em si a Educação Ambiental, como, por exemplo, com o aproveitamento do material da propriedade, de modo sustentável, e a oportunização às pessoas que fazem turismo e visitam o local de conhecerem tais práticas e processos. O experienciar das pessoas a partir das relaçóes do corpo com o entorno, o ser no mundo, imersos numa única trama e, como revelaria Merleau-Ponty (2006, p. 7-8), como participantes do "Uno sem dividi-lo”. Segundo ela, também, não há necessidade do uso de agrotóxicos

\footnotetext{
4 [...] el medio ambiente no es um tema, sino una realidad cotidiana y vital.

$5 \quad$ [...] se situa en el centro de un proyecto de desarrollo humano.

6 [...] esfera de relación a Oikos (éco), la casa de vida compartida en la que existe una forma de alteridad relacionada con la red de otros seres vivos.
} 
que contaminam o ambiente, em especial a água que as pessoas consomem; o "controle" (Dida, c. p.) - que interpretamos como relacionado aos organismos invasores - mantém-se quando há variedade de espécies de plantas em conjunto, sem a necessidade do uso de veneno. Compreendemos este relato como uma crítica ao emprego de produção agrícola que se utiliza de agrotóxicos para o controle de invasores. Por exemplo, no caso da monocultura que cultiva áreas extensivas de uma mesma espécie de planta, favorecendo a incidência de invasores e gerando o aumento na aplicaçáo de produtos agrícolas tóxicos, considerados como possíveis carcinogênicos pelo Ministério da Saúde (BRASIL, 2015). Somente em 2019, até o mês de setembro, foi liberado no Brasil o registro de 325 agrotóxicos diferentes, de acordo com o Ministério da Agricultura (BRASIL, 2019). Ainda, conforme a mesma fonte, há cerca de 2.000 novos produtos agrícolas para serem avaliados nos próximos meses, mostrando um aumento acelerado no uso de substâncias tóxicas na agricultura brasileira.

A coordenadora do Projeto Gaia Village acredita que - no senso comum nas escolas quem geralmente faz Educação Ambiental são professores de Ciências ou Geografia, às vezes, outra disciplina de um professor mais envolvido. Para a entrevistada, o termo Educação Ambiental é usado "porque é a linguagem que as pessoas compreendem e entendem" (Sandra, c. p.). No entanto, afirma que prefere trabalhar com o termo educação. Nesse caso, ela se aproxima da perspectiva Freireana de educação, que não se impõe como algo já dado, mas resulta das relaçóes individuais e coletivas em seus contextos sociais e culturais. Para Freire (1994), a verdadeira educação só é possível por meio do diálogo, do encontro entre os sujeitos. A aprendizagem como ato dialógico, na concepção de Carvalho (2004), requer a compreensão das relaçóes mútuas entre a sociedade e a Natureza. Porém este diálogo não se reduz a uma simples conversa. Em essência, de acordo com Freire (1994), é fundamentado pelo amor ao mundo, pelo amor à vida e às outras pessoas. Pensamos que seja este amor que aproxima o eu e o mundo, que aproxima o eu e o outro como humanidade e como meio ambiente, que instiga ao cuidado com o outro, que gera a conexão responsável de cuidado também com a Natureza.

Para Merleau-Ponty (1999), a fala é a única capacidade humana capaz de construir um saber intersubjetivo, que envolve o conhecimento entre consciências de pessoas diferentes. Nesta perspectiva, acreditamos ser possível aos sujeitos aprenderem a fazer a conexão responsável de cuidado entre o eu e a Natureza por meio do diálogo - na visão Freireana (1994) - e da construçáo intersubjetiva do saber - na concepçáo Merleau-Pontyana (1999, 2006). Neste sentido, consideramos que o ponto de vista da coordenadora do Gaia Village se insere na abordagem de educação que Freire (1994) e Brandão (2005) defendem também quando a entrevistada salienta que: 
É necessário reaprender, reeducar as pessoas pra ter essa conexão com a Natureza, de reaprender a viver de acordo com os ritmos, com os ciclos. Náo que nós voltemosa ser pescadores e coletores de sementes. Mas, que a gente saiba compreender que laranja não tem no mercado de janeiro a janeiro. Não deveria, não deveria ter, pelo menos. Não deveria ter mamão de janeiro a janeiro, coisas mínimas. De que tudo tem um custo. [...] um leite que fica dois, três meses numa caixa e não estraga não é algo natural. Tem algo mais ali. É essas coisas básicas, de que as nossas crianças tão perdendo, que a gente tá perdendo, da cultura do imediatismo, do 'eu quero tudo pronto, aqui e agora!', 'não tenho tempo!' [...] Entáo, se perdeu esse contato com o sagrado. Quando falo no sagrado, é o sagrado no sentido mais amplo, mesmo, da Natureza, do sagrado que somos como corpo, mente e alma, desse espaço que a gente convive aqui, que a gente deveria tá saboreando, aproveitando e usando - entre aspas - de uma maneira mais harmoniosa, mais digna [sic] (Sandra, c. p.).

Brandão (2005, p. 39), estabelece uma conexão com o sagrado ao explicar que os desafios proporcionados pelos novos paradigmas de pensamento exigem dos sujeitos a compreensão da prática do estudo e da reflexão "como uma tarefa verdadeiramente espiritual", que "aprender a saber e adquirir conhecimento aberto pelas ciências não se opóe em nada ao meu crescimento espiritual" (BRANDÁO, 2005, p. 39). Para Pereira (2016), o sentido do desenvolvimento espiritual, de uma reaproximação com a dimensão cósmica, faz- se fundamental para o enfrentamento das amplas crises existentes na atualidade.

Pensamos que o científico e o sagrado podem conviver em diálogo, no sentido dialógico de Freire (1994), e que a vivência com a Natureza impregnada de percepçóes e sentimentos pode ser um caminho possível para que isso ocorra. E, para além disso, acreditamos que, na perspectiva de uma "Pedagogia Cosmocena" (PEREIRA, 2016, p. 75), possam ser construídos processos que transcendam a dimensão meramente física e contemplem uma "aprendizagem transcendental" (2016, p. 88).

O Centro de Educação Ambiental NaturGut Ophoven, como membro da Organização das Naçóes Unidas (ONU), adota a concepção e abordagem da Educação para o Desenvolvimento Sustentável - que discute formas e políticas de ensino para a sustentabilidade - e se orienta pelas políticas sugeridas pela ONU de Educação para o Desenvolvimento Sustentável (BRASIL, 2016). Com base nos relatos de Ute, as escolas do município de Leverkusen têm seus pressupostos teóricos próprios e o Centro complementa estes estudos teóricos com as vivências e experiências práticas no, sobre, por e para o meio ambiente ${ }^{7}$, com enfoque na

7 Conforme Sauvé e Orellana (2006, p. 275-276), el objeto de la educación ambiental no es el médio ambiente como tal, sino que nuestra relación com él. Cuando se habla de uma educación 'sobre', 'em', 'por' y 'para' el médio 
mudança climática e a energia. Para a coordenadora, nem sempre é fácil para um professor levar seus alunos para o meio ambiente ou para um museu. Entáo, facilita para o professor de Biologia do $4^{\circ}$ ano ou Geografia do $6^{\circ}$ ano, por exemplo, encontrarno NaturGut Ophoven cursos e projetos específicos para suas áreas de interesse.

Entre os materiais produzidos pelo Centro, há um programa pedagógico (NATURGUT OPHOVEN, 2014) e um calendário anual (NATURGUT OPHOVEN, 2015) nos quais constam a descrição das açóes e o calendário de atividades por tema e idade. São materiais bem organizados, de fácil entendimento, que orientam o professor sobre as atividades. De forma semelhante à Pousada Vitória e ao Gaia Village, o Centro atua de modo complementar à escola formal.

Com base nas concepções de Educação Ambiental que assumem, emergem nos espaços estudados temas norteadores e subtemas trabalhados em diferentes projetos, programas e atividades. Na Pousada Vitória, de acordo com o site (ACOLHIDA DA COLÔNIA, 2015), as atividades são voltadas, sobretudo, ao agroturismo ecológico. A partir deste tema principal, dos relatos da proprietária e da nossa observação, são trabalhados os seguintes temas: agricultura orgânica familiar, importância das abelhas, pesca de açude, trilha, preservação de Mata Atlântica e a sustentabilidade nas estruturas e processos. No Gaia Village, conforme relato de Sandra, o enfoque principal do projeto são a Educação Ambiental e a sustentabilidade, cujos subtemas/programas decorrentes, segundo o site (GAIA VILLAGE, 2015) e nossa observação participante, são: sensibilização ambiental, tecnologias ambientalmente amigáveis, produção rural sustentável, pastoreio de búfalos, desenvolvimento humano, preservação e restauração de ecossistemas, saúde sustentável, infraestrutura de bioconstrução, estudos e pesquisas e trilhas. No Centro NaturGut Ophoven, de acordo com o site (NATURGUT OPHOVEN, 2015) e com as anotaçóes de campo das observaçóes participantes, o principal tema abordado é a mudança climática, cujos subtemas decorrentes são: energia (renovável, consumo consciente, economia, tecnologias e mobilidade urbana), meio ambiente e natureza, jardins (de aromas, de plantas medicinais e de sentidos), horta orgânica, importância da abelha, alimentação saudável e trilhas.

Os temas principais de cada espaço, por mais que tenham algumas diferenças de enfoque, aproximam-se por abrangerem a sustentabilidade em seus processos e estruturas. Os três espaços visitados apresentam abordagens/pressupostos em

ambiente, [...] no se está definiendo el objeto central de la educación ambiental, que es la red de relaciones entre las personas, su grupo social y el medio ambiente. Para as autoras, o meio ambiente é uma realidade tão complexa que uma educación ambiental limitada a uma u outra de estas representaciones sería incompleta y responderia a uma visión reducida de la relación com el mundo (Sauvé; Orellana, 2006, p. 276). 
comum como a agricultura orgânica e a preocupação com os alimentos; tecnologias para estruturas e processos de baixo impacto; preservação de ecossistemas e trilhas. Além destes temas, a Pousada Vitória e o NaturGut Ophoven também apresentaram o tema comum acerca da importância da abelha no ecossistema.

A diversidade de temas encontrados nos três espaços pesquisados assemelha-se, em alguns aspectos, aos resultados dos estudos de Silva (2004), em que observou o tratamento de temáticas, como: meio ambiente e Natureza, recuperaçáo de áreas degradadas, plantas medicinais, agricultura, energia, Educação Ambiental, apicultura, pecuária e arquitetura bioclimática (à qual o Projeto Gaia Village se refere como bioconstrução). Além destes, os espaços visitados também apresentaram temas diferenciados, como agroturismo ecológico, preservação, sustentabilidade, sensibilização, desenvolvimento humano, saúde sustentável, mudança climática, jardins e alimentação saudável, demostrando que há um leque considerável de possibilidades temáticas a serem trabalhadas em espaços educadores que buscam a sustentabilidade em suas estruturas e processos. Os temas discutidos também abarcam os sugeridos por Trajber e Czapsky (2010), como o uso de energias e tecnologias limpas, a segurança alimentar, a interação humana, a água (no que tange às estruturas e processos sustentáveis e à Educação Ambiental), a biodiversidade (nas vivências no e com os ambientes proporcionados pelo espaço) e economia local (na valorizaçáo da comunidade do entorno, consumindo e oferecendo alimentos orgânicos produzidos localmente).

Todos os temas que emergiram das entrevistas, documentos e observaçóes são trabalhados, nos três espaços, por meio de diferentes processos envolvendo as atividades. Na Pousada Vitória, conforme relato da proprietária, as atividades de agroturismo ecológico realizadas neste espaço envolvem: agricultura orgânica familiar, turismo de final de semana, Educação Ambiental com escolas e visitantes, apicultura de melipona (abelha sem ferrão); diversificação de produção de orgânicos da pousada, relaçóes amigáveis e cooperativas entre os diferentes proprietários rurais orgânicos da região, produção de peixes com manejo ecológico, uso de tecnologias de baixo impacto nas estruturas (uso de claraboias para iluminaçáo interna, uso de uma serpentina para aquecimento da água no calor do fogão a lenha e uso de madeira de demoliçáo sem tratamento com inseticidas), economia de energia, preservação de Floresta Atlântica e trilha, dentre outras.

No Gaia Village, a observação, o relato da coordenadora e o estudo de documentos indicaram que seus processos ocorrem por meio de: Projeto e Relatório Anual (PREFEITURA MUNICIPAL DE GAROPABA; FUNDAÇÃO GAIA; GAIA VILLAGE, 2014) (que norteiam as atividades no espaço e relatam o que já foi realizado), Educação Ambiental com escolas (por meio do Programa Mostra José Lutzenberger) e demais visitantes, multiplicação de conceitos e práticas (por meio das palestras, cursos e oficinas), rede de parcerias locais, 
nacionais e internacionais, fortalecimento da agricultura orgânica pela produção rural sustentável, articulação de redes comunitárias (como escolas, associaçóes, conselhos e grupos de pescadores e agricultores, por exemplo), parceria náo financeira com o município (por meio do Programa Mostra José Lutzenberger), parcerias com universidades e outras entidades (em geral, na área de estudo e pesquisa), pecuária orgânica de búfalos (por meio de pastoreio voisin e uso de medicamentos veterinários naturais, uso e disseminaçáo de tecnologias de baixo impacto (aquecimento solar da água, produção de energia eólica e fotovoltaica, banheiros secos de compostagem, uso de madeira de demolição, ventilação cruzada e telhado verde), economia de energia, bioconstrução (onde as construçóes acompanham a topografia e as características do ambiente), oferta de cursos, palestras e oficinas, e locação do espaço para eventos (relacionados com a saúde e o bem-estar, terapias alternativas, espiritualidade), dentre outros.

No Centro NaturGut Ophoven, as atividades envolvem os seguintes processos: planejamento, gestão e avaliação de açóes e projetos - a partir da elaboração de projetos e culminando com a elaboraçáo dos relatórios, Educação Ambiental com escolas e demais visitantes (por meio de projetos, cursos e a interatividade das estruturas), cultivo orgânico e oferta de alimentos orgânicos da regiáo, inclusão de pessoas de baixa renda (por meio de projetos específicos), Global Learning (no qual as crianças podem aprender e partilhar experiências sobre as diferentes culturas), experiências vivenciais ao ar livre, experiências práticas no museu, sensibilização (por meio de vivências que exploram os diferentes sentidos), cursos, trilhas, separação do lixo, parceria financeira com o governo municipal e fundaçôes, atividades com universidades, autoavaliação (por meio de questionário aos participantes e testes de programas internos, além de uma avaliaçáo externa realizada por um escritório fora do Centro), e a locação do espaço para festas.

Sobre as experiências vivenciais ao ar livre, é importante ressaltar que, conforme as anotações de campo sobre a observação participante, as atividades instigavam as crianças à percepção do ambiente por meio dos diferentes sentidos - visão, audição, tato, paladar e olfato - como forma de sensibilizá-las sobre a temática trabalhada. À luz da Fenomenologia em Merleau-Ponty (1999), o sentir é importante pelo fato de habitar a visão das pessoas, de fazer parte imanente da existência humana, pois ao ato de conhecer são impressos sentimentos relacionados às experiências vividas, influenciando na atribuição de sentidos a essas vivências. A apreensão sensível do ambiente (como cheiros, contatos e outros sentidos) vai ao encontro das recomendaçóes de Sato (2004) para metodologias em Educação Ambiental, o que permite a obtenção de mais informaçóes e significados sobre o ambiente, associando as emoçôes com o pensamento crítico. Uma expansão disso é proposta por Sato, Silva e Jaber (2018, p. 52), acerca de um currículo fenomenológico: 
É aqui, que um currículo fenomenológico traz, por sua configuração dialógica, um caráter existencial e holístico, e permitiria pôr as questóes da consciência individual e singular no âmbito das preocupaçóes coletivas da humanidade. Tal currículo levantaria perguntas, suspeitando das respostas. Permitiria reencontrar, no coração humano, por sua singularidade-universal, as referências capazes de dar sentido e perspectiva a um diálogo com as diferenças: todos somos universalmente diversos.

Os processos destacados nos três espaços visitados mostraram-se bastante diversificados e mais abrangentes do que os encontrados por Silva (2004) em seus estudos. As fontes de informação buscadas indicaram ações particulares, mas também atividades em comum. Como processos semelhantes entre os três lugares visitados, foram encontrados: Educação Ambiental com escolas e visitantes, atividades rurais orgânicas (tanto relacionadas às hortas quanto à pecuária, como as abelhas e/ou os búfalos), trilhas, separação de lixo, uso de tecnologias de baixo impacto, economia de energia e a preservaçáo de ecossistemas. Tanto o Gaia Village quanto o NaturGut Ophoven apresentaram processos em comum, quais sejam: desenvolvimento de um projeto concreto norteador e o relatório das atividades já realizadas; produção de energia eólica e fotovoltaica (sendo que o Centro NaturGut Ophoven é neutro em carbono, enquanto no Gaia a produção é específica em uma das estruturas prediais); parcerias com universidades, município (no Gaia Village, a parceria não é de cunho financeiro, já no NaturGut Ophoven, ocorre uma parceria que fomenta financeiramente os processos e estruturas) e outras entidades; oferta de cursos dentro do espaço; e a locação do espaço para eventos (no Gaia Village há um espaço aberto para reunióes e eventos comunitários diversos, enquanto no NaturGut Ophoven a locação é específica apenas para aniversários infantis).

Uma característica importante observada no Projeto Gaia Village e no Centro de Educação Ambiental NaturGut Ophoven é a concretização de um projeto norteador dos princípios e atividades do Centro, assim como a confecção de relatórios sobre os resultados das ações realizadas. Este aspecto contrasta com os estudos de Silva (2004), quando afirma que uma das grandes dificuldades dos Centros de Educação Ambiental do Brasil é a falta de um planejamento, sem a mínima discussão básica de objetivos e metas - o que acaba conferindo uma abordagem menos pedagógica e mais construtiva. No caso destes dois espaços visitados, ambos se mostraram preocupados com uma organização mais político- pedagógica, o que favorece o sucesso no planejamento e execução das açóes e a discussão sobre os resultados, possibilitando a melhoria dos processos e estruturas. Outro fator levantado 
por Silva (2004) é a avaliação dos processos, algo que no presente estudo foi evidenciado pelo Centro NaturGut Ophoven, mostrando que, possivelmente, os espaços visitados no Brasil ainda carecem desta necessidade organizacional. $\mathrm{O}$ processo de avaliação das atividades executadas nesses espaços, de acordo com Silva (2004), permite o acompanhamento, replanejamento e retomada das açóes, que favorecem melhorias e fortalecem os futuros projetos. Contudo, ressaltamos que a avaliação deve ser muito bem estruturada no sentido de servir ao propósito de diagnosticar as estruturas e processos, no intuito de buscar soluçóes aos problemas e reforçar aquilo que teve êxito. Pensamos que a avaliação não pode ser usada como instrumento de controle, mas sim de diagnóstico e reorganização.

Os Espaços Educadores Sustentáveis encontram-se em um processo de construção permanente. Foi interessante constatar o interesse em projetos futuros que almejam melhorar as estruturas e processos ligados à educação e à sustentabilidade. Conforme relato da proprietária da Pousada Vitória, seus planos futuros incluem trabalhar com o tema das ervas medicinais, pois, além de aproveitar plantas existentes no espaço, também poderá oferecer banhos medicinais e massagem: "Ter uma pessoa especializada em fazer massagem. Porque já tem uma demanda, já tem uma procura, e hoje, no nosso município, ainda não tem ninguém que faça massagem" (Dida, c. p.). Este relato indica que existe uma demanda por esta atividade e que pode ser uma potencial fonte de renda à pousada, por ser um projeto pioneiro no município.

$\mathrm{O}$ aspecto acima citado reporta-nos à questão da corporeidade (MERLEAUPONTY, 1999, 2006), uma vez que vivenciamos o mundo como sujeitos corpóreos. Assim, o cuidado com o corpo remete-nos também ao cuidado com o meio ambiente, ou, pelo menos, dever- nos-ia fazer refletir sobre isso. Se nosso corpo não está bem cuidado, não podemos vivenciar o mundo em sua plenitude. Do mesmo modo, se o ambiente não está em equilíbrio dinâmico, não teremos uma relação saudável com ele.

A entrevistada (Dida) também revelou que há um projeto futuro para que a estrutura física seja autossustentável, com uso da energia solar.

No Gaia Village, de acordo com o relato da coordenadora, os projetos futuros para o desenvolvimento da propriedade são direcionados no sentido de favorecer a integração entre as pessoas e o meio ambiente. Deste modo, como enfatiza, o Gaia pretende continuar a trabalhar "[...] esse processo de educação, educação, educação, educação com a comunidade" (Sandra, c. p.), e também intensificar a participação em conselhos e instâncias de decisão, visando a qualificar as decisóes dos gestores e das pessoas em geral. Cabe ressaltar que a ênfase dada por Sandra à educação denota a importância que dá ao processo educativo efetuado por espaços como esse. 
Referindo-se à realidade nacional, ela explica que "num país em que a legislação ambiental é riquíssima e vasta, tá mais do que evidente que náo basta ter uma legislação ambiental dura. Precisa ter fiscalização, precisa ter critérios para as coisas acontecerem" [sic] (Sandra, c. p.). Acrescenta, ainda, que, infelizmente, até pelo novo Código Florestal ficou evidente que quem poluía e devastava foi "premiado", "anistiado" (Sandra, c. p.). Para ela, aquele que sempre cuidou do espaço natural náo recebe nem crédito ambiental, ou, no máximo, recebe a sugestão de transformar a área preservada num parque. "Então, geralmente, quem cuida é punido" (Sandra, c. p.). Essas palavras da coordenadora do Gaia Village fazem lembrar Merleau-Ponty (2006, p. 500), quando enfatiza que "só percebemos um mundo se, antes de serem fatos constatados, esse mundo e essa percepção forem pensamentos nossos". Ou seja, a percepção de um sujeito é o fundo sobre o qual todos os atos se destacam; o mundo é o meio natural e o campo de todos os pensamentos e de todas as percepçóes (MERLEAU- PONTY, 2006). Logo, somos embebidos de subjetividade e corporeidade em nossa relação com o mundo.

Visando a dar continuidade ao trabalho de visitação e educação no espaço Gaia Village, a coordenadora afirma: "A gente precisa avançar além disso. Então, desse tempo todo, digamos assim, de 20 anos de trabalho quase que silencioso, aqui, de receber as pessoas, de educar, a gente sabe que precisa dar um passo além" (Sandra, c. p.). Então, atualmente, o projeto está fazendo um estudo denominado "Macrodiagnóstico Ambiental" (Sandra, c. p.). Esclareceu que foram convidadas pessoas de diferentes áreas (geógrafos, geólogos, botânicos e antropólogos) para fazerem um diagnóstico do que existe no Gaia Village, hoje, em termos de floresta, diversidade, como é o solo e como está a questão da água, para, então, num segundo momento, olhar para esses lugares - ressalvadas as Áreas de Preservação Permanente (APP) e Reserva Legal - e pensar no que pode ser transformado, se num espaço para as crianças, ou uma horta, uma pequena casa, ou até algo mais comercial. Destacou a necessidade de, então, desenhar um projeto - com a ajuda de arquitetos e urbanistas - ao qual se refere como "Projeto de Assentamento Humano de Baixo Impacto" (Sandra, c. p.), que, na concepçáo da coordenadora, integre as pessoas com a Natureza, sem isolá-las dela. Salientou que há possibilidade da construção de uma pequena vila diferenciada, ou um condomínio diferenciado de baixo impacto, como também uma Escola de Gaia, como uma Green School, por exemplo, "[...] quando o Gaia inteiro pode ser visto como uma escola" (Sandra, c. p.). A coordenadora considera - sonho seu como educadora - a concretizaçáo de uma escola mais qualificada, que não desconsidere as outras escolas, mas que agregue novos valores às escolas atuais do ensino regular, onde as crianças e jovens possam ser protagonistas de sua história. O que se assemelha ao "sujeito 
ecológico", expressão de Carvalho (2004), e que se refere a quem se propóe a gerar transformaçóes de forma crítica, ética e responsável. Um ser capaz de "ler e interpretar um mundo complexo e em constante transformação", compreendê-lo e agir nele de forma crítica, transformadora e emancipatória (CARVALHO, 2004, p. 75), que assume suas responsabilidades individuais e coletivas no sentido de buscar meios à superação dos problemas sociais e ambientais. Na verdade, esse deveria ser o compromisso da educaçáo em todos os espaços que se dizem educadores.

O Centro de Educação Ambiental NaturGut Ophoven, semelhante ao caso da Pousada Vitória, também planeja desenvolver um novo projeto relacionado ao tema das plantas medicinais, mais especificamente um jardim-farmácia. Além deste projeto, a coordenadora do Centro enfatiza que existem planos para intensificar o processo de inclusão, onde todos possam aprender juntos, o que relata ser muito importante na Alemanha. No site do Centro (NATURGUT OPHOVEN, 2015) há um projeto inclusivo chamado Kreuzfahrt Familie (Cruzeiro Família), em que famílias de baixa renda vivenciam atividades educativas durante uma semana de férias. Projetos futuros de inclusão, segundo a coordenadora, abrangem a acessibilidade para pessoas com deficiência que usam cadeira de rodas, buscando construir e adaptar estruturas. Também, um projeto que ela chamou de "Global Learnig" (Ute, c. p.) - e que pode ser traduzido como aprendizagem global - envolve crianças e jovens imigrantes em atividades onde podem aprender uns com os outros, trocar experiências entre as diferentes culturas, em encontros semanais. Afirma, ainda, não possuírem recursos financeiros para concretizá-lo, então elaborarão um novo projeto e buscarão parceria entre instituições ambientais na Alemanha.

Os planos futuros dos três espaços estudados incluem a preocupação com a estrutura física adaptada a determinados projetos, como na Pousada Vitória - que pretende buscar a autossustentabilidade investindo futuramente em um projeto de energia solar; no Projeto Gaia Village - que almeja construir um assentamento humano de baixo impacto; e no Centro de Educação Ambiental NaturGut Ophoven - que busca recursos para construir e adaptar espaços para a acessibilidade inclusiva. Tanto o Centro na Alemanha quanto a Pousada no Brasil mostraram a intençáo de desenvolver atividades com plantas medicinais. Esta preocupação com a melhoria e adequação de estruturas se alinha à proposta incentivada no Plano Nacional de Mudança do Clima (BRASIL, 2008), que propõe, em escolas e universidades, a readequação dos edifícios/construçôes no sentido da sustentabilidade e que, posteriormente, foi complementada pelo Programa Mais Educação (BRASIL, 2010), que incluiu nesta reestruturação a preocupação com a acessibilidade. 


\section{Algumas considerações num caminho em construção}

À luz da Fenomenologia Merleau-Pontyana (1999), o espaço - além de físico - é relacional e em processo. É um espaço vivido por um sujeito, corpóreo, com sentimentos, que remete às memórias vividas e imprime sentido às coisas e às situações. Por isso, a importância em se considerar, na estruturação e nos processos que acontecem nos espaços que se propóem serem educadores e sustentáveis, o firme propósito de que intencionalmente sejam criados e estruturados contemplando a vivência e a experimentação dos sujeitos, oportunizando, assim, criar memórias, o conhecimento de si mesmos, entre si e do mundo.

Considerando esta perspectiva, a pesquisa trouxe elementos sobre Educação Ambiental que sinalizam diferentes abordagens nos espaços estudados: a abordagem do respeito e do cuidado à vida e à Natureza; a abordagem da educação em um sentido amplo, que abarca aspectos como a espiritualidade e o contato com o sagrado; e a abordagem da Educação Ambiental como política educacional que foi observada na implementação da Educação para o Desenvolvimento Sustentável no Centro de Educação Ambiental na Alemanha. Este leque diferenciado de abordagens da Educação Ambiental leva-nos a inferir que, mesmo sendo um fenômeno discutido no Brasil e em outras partes do mundo, como na Alemanha, as pessoas que trabalham nos diferentes espaços têm concepções diferentes sobre o que é Educação Ambiental, justificadas pelo modo particular com que cada sujeito percebe o mundo, considerando a Fenomenologia da percepção Merleau-Pontyana.

A pesquisa aponta, ainda, que a experiência sensorial coletiva em espaços intencionalmente criados para a finalidade educativa socioambiental também se mostrou importante processo sensibilizador, sinalizando para a valorização da vivência intersubjetiva e para a estruturação dos Espaços Educadores Sustentáveis. No Centro de Educação Ambiental na Alemanha, as crianças que vivenciaram estas experiências mostraram espontaneidade em oferecer ajuda aos colegas, em colaborar no auxílio aos desafios propostos na trilha e transpareceram ter se apropriado de muitos aspectos da experiência, durante o feedback observado no final do curso. A vivência foi significativa para as crianças e foi influente na relação entre os sujeitos, enaltecendo a necessidade de transcender à dimensão física.

É necessário, também, ter uma preocupação com os sujeitos, tanto com aqueles que visitam quanto com os que promovem açóes naquele espaço, bem como buscar meios de envolvê-los nas propostas e atividades de modo integrado, para que estas tenham significado e possibilitem a construção do conhecimento e a compreensão de seu papel no mundo com vistas a mudanças concretas na sociedade. 
As atividades promovidas pelos sujeitos que atuam nos Espaços Educadores Sustentáveis podem ser direcionadas para todos os públicos, de modo a favorecer a imersão dos sujeitos nos ambientes e promover a inclusão social. Aspectos pertinentes à inclusão social que emergiram neste estudo foram a possibilidade e a intencionalidade de desenvolver atividades para todos os públicos, considerando a preocupação com a acessibilidade de pessoas com deficiência, a integração destas, de pessoas de baixa renda e de imigrantes nos seus processos educativos, como observado no NaturGut Ophoven.

Outra possibilidade que emergiu é a do macrodiagnóstico ambiental, um projeto futuro do Gaia Village, mas que é pertinente a todos os espaços que intencionam a formação e constituição de Espaços Educadores Sustentáveis. Diz respeito à importância de se conhecer o lugar onde vai ser criado, as suas características físicas e ecológicas, a comunidade do entorno, para se desenhar um projeto que considere a dinâmica social e ecológica local em sua implementação e continuidade.

Ainda, outra peculiaridade que emergiu foi a possibilidade de construção de uma escola sustentável - meta da coordenadora Sandra (do Gaia Village) náo necessariamente uma escola formal, ou uma que desconsidere as escolas de ensino regular, mas que seja complementar às diferentes formas de educação. Que seja um espaço de educação vivencial, crítica, transformadora e que encoraje o protagonismo das crianças e jovens.

Sobre a questáo da agricultura orgânica, a permacultura mostrou-se uma possibilidade viável de produção de alimentos por meios sustentáveis aproveitando energias renováveis, diversificando espécies de cultivo, usando adubação orgânica, evitando o uso de agrotóxicos e insumos agrícolas, e fazendo manejo sustentável. E dentro do contexto de agricultura orgânica, a formação de cooperativas apresentou-se pertinente à sustentabilidade socioambiental, por se utilizar de processos de produção em ciclo fechado.

Educação e sustentabilidade socioambiental não são relacionadas somente com as estruturas, mas, sobretudo, com os processos e de uma forma integrada. Nesses processos, pode ser abordada uma multiplicidade de temas como os que emergiram na pesquisa, dentre eles: Educação Ambiental e sustentabilidade, agroturismo ecológico, agropecuária orgânica, preservação, conservação e restauração de ecossistemas naturais, destino apropriado do lixo, o uso da compostagem, bioconstrução e os destacados por Silva (2004).

Estes temas podem ser abordados de variadas formas: projetos, cursos, palestras, oficinas, consultorias, por meio de estímulo à organizaçáo social local, visitas orientadas, trilhas interpretativas, atividades de agroturismo ecológico, permacultura, pecuária com manejo ecológico, alimentação orgânica, uso de tecnologias e materiais de baixo impacto, economia de energia, articulação de 
redes comunitárias, bioconstrução, estudos e pesquisas, experiências sensoriais/ interativas e de diálogo ao ar livre ou em espaços alternativos, e as demais destacas neste estudo.

Trabalhar com processos educativos remete ainda à reflexão acerca da formação de educadores, já que almejamos a constituição de um educador crítico, articulador, promotor de açóes dinâmicas, que atue junto aos educandos, estimulando-os, capacitando-os para a construçáo de novas realidades.

Neste sentido, pensamos que professores/educadores influenciam diretamente na qualidade do conhecimento potencial dos alunos/educandos, e, aqui, reportamo-nos à questáo da responsabilidade do trabalho do educador. $\mathrm{O}$ fomento financeiro e estrutural governamental à formação, à valorização salarial e às boas condiçóes de trabalho dos professores/educadores é fundamental para que eles tenham vivências educativas integradas, que experimentem o mundo e proporcionem experiências educativas de qualidade, coerentes com a sustentabilidade socioambiental, que zelem pelo cuidado e que valorizem a vivência sensorial no meio ambiente em seus processos.

Contudo, a exemplo de Geraldo Vandré, na clássica letra de Caminhando "[...] Vem, vamos embora que esperar não é saber, Quem sabe faz a hora, não espera acontecer $[. .$.$] ", não podemos, como educadores que somos, esperar à beira do$ caminho que a valorizaçáo do professor aconteça para então atuarmos em favor de uma educação política e dialógica na formação do cidadão. É fundamental que recuperemos nossa capacidade de lutar e seguir em frente, construindo possibilidades em processos nem sempre tão francos ao exercício da democracia e da liberdade.

Assim, nos dias atuais, todos os espaços educacionais necessitam comprometerse com uma formação crítica, ética, responsável, sustentável e capaz de formar cidadãos atuantes que promovam a salvaguarda do patrimônio socioambiental nacional com liberdade e amor.

\section{Referências}

ACOLHIDA DA COLÔNIA. Disponível em: acolhida.com.br/propriedades/ encostas-da- serra-geral/santa-rosa-de-lima/pousada-vitoria-ou-pousada-da-dida. Acesso em: 22 out. 2015.

BRANDÃO, C. R. As Flores de Abril: movimentos sociais e educação ambiental. Campinas: Autores Associados, 2005.

BRASIL. Diretrizes Curriculares Nacionais para a Educaçáo Ambiental. Brasília: MEC,2012. 
Posicionamento do Instituto Nacional de Câncer José Alencar Gomes da SilvaAcerca dos Agrotóxicos. 2020. Disponível em:

https://www.inca.gov.br/publicacoes/notas-tecnicas/posicionamento-do-incaacerca-dos-agrotoxicos. Acesso em: 13 out. 2021.

Diário Oficial traz Publicaçáo de Defensivos Agrícolas com Genéricos eProdutos mais Modernos. 2019. Disponível em:

https://www.gov.br/agricultura/pt-br/assuntos/noticias/diario-oficial-trazpublicacao-de-defensivos-agricolas-com-genericos-e-produtos-mais-modernos Acesso em: 13 out. 2021.

. Educaçáo para o Desenvolvimento Sustentável. Disponível em:

http://www.mma.gov.br/port/sdi/ea/deds/pdfs/sumexec_eds.pdf. Acesso em: 29 out. 2016.

. Plano Nacional sobre Mudança do Clima. Brasília, Governo Federal, 2008.

. Decreto no 7.083, de 27 de janeiro de 2010. Dispõe sobre o Programa

Mais Educação. Disponível em: http://www.planalto.gov.br/ccivil_03/_ ato2007-2010/2010/decreto/d7083.htm. Acesso em: 13 out. 2021.

CARVALHO, I. C. de M. Educação Ambiental: a formação do sujeito ecológico. São Paulo:Cortez, 2004.

COLAIZZI, P. F. Psychological Research as the Phenomenologist Views It. In: VALLE, R. S.; KING, M. Existential Phenomenological Alternatives for Psychology. New York: Oxford University Press, 1978. p. 48 - 71.

FREIRE, P. Pedagogia do Oprimido. 17. ed. Rio de Janeiro: Paz e Terra, 1994. GAIA VILLAGE. Projeto Ambiental Gaia Village. Disponívelem: http://www. gaia.org.br/. Acesso em: 23 nov. 2015.

MERleAU-PONTY, M. Fenomenologia da Percepçáo. São Paulo: Martins Fontes, 1999.

A Natureza. São Paulo: Martins Fontes, 2006.

MOREIRA, D. A. O Método Fenomenológico na Pesquisa. São Paulo: Pioneira Thomson Learning, 2002.

NATURGUT OPHOVEN. NaturGut Ophoven - das pädagogische Programm. Leverkusen: NaturGut Ophoven. Abr. 2014.

. Disponível em: www.naturgut-ophoven.de. Acesso em: 12 jun. 2015. 
PEREIRA, V. Ecologia Cosmocena: a redefinição do espaço humano no cosmos. Juiz de Fora, MG: Garcia Edizioni, 2016.

PREFEITURA MUNICIPAL DE GAROPABA; FUNDAÇÃO GAIA; GAIA VILLAGE. 13a Ediçáo do Programa de Sensibilizaçáo e Educaçáo Ambiental Prof. José Lutzenberger: escola amiga do ambiente. Garopaba: Prefeitura Municipal de Garopaba, Fundação Gaia e Projeto Gaia Village, 2014.

SANDERS, P. Phenomenology: a new way of viewing organizational research. Academy of Management Review, v. 7, n. 3, p. 353 - 60. 1982.

SATO, M. Educação Ambiental. São Carlos: RiMa, 2004.

. Clusters da Educação Ambiental: do eu isolado ao nós coletivo. In: SATO, Michele et al. Escola, Comunidade e Educaçáo Ambiental: reinventando sonhos, construindo esperanças. Cuiabá: Print, 2013. p. 15-29.

SATO, M; SILVA, R.; JABER, M. Educação Ambiental: tessituras e esperanças. Cuiabá: Editora Sustentável, EdUFMT, 2018.

SAUVÉ, L.; ORELLANA, I. 1. La Formación continua de profesores en educación ambiental: la propuesta de EDEMAZ. In: SANTOS, J. E. dos; SATO, M. (Org.). A Contribuiçáo da Educaçáo Ambiental à Esperança de Pandora. 3. ed. São Carlos: RiMa, 2006. p. 273-287.

SILVA, F. D. Histórico, Classificaçáo e Análise de Centros de Educaçáo Ambiental no Brasil. 2004. 194 f. Dissertação (Mestrado em Recursos Florestais - conservação de ecossistemas florestais). ESALQ/USP Piracicaba, 2004.

TRAJBER, R.; CZAPSKI, S. Macrocampo Educaçáo Ambiental - Mais Educação: a educação integral em escolas sustentáveis (versão preliminar). MEC. 2010. Disponível em:http://portal.mec.gov.br/index.php?option=com_docma n\&view=download\&alias=8213 - educacao-ambiental-final-versao-preliminarpdf\&Itemid=30192. Acesso em: 25 set. 2015.

TRAJBER, R.; SATO, M. Escolas Sustentáveis: incubadoras de transformação nas comunidades. REMEA Revista Eletrônica do Mestrado em Educaçáo Ambiental, v. especial. set. 2010. Disponível em: http://www.seer.furg.br/remea/ article/view/3396/2054. Acesso em: 29 ago. 2015. 